\title{
Targeted gene panel for genetic testing of south Indian children with steroid resistant nephrotic syndrome
}

\author{
Annes Siji ${ }^{1 \dagger}$, K. N. Karthik ${ }^{1 \dagger}$, Varsha Chhotusing Pardeshi ${ }^{1 \dagger}$, P. S. Hari ${ }^{1}$ and Anil Vasudevan ${ }^{1,2^{*}}$ (D
}

\begin{abstract}
Background: Steroid resistant nephrotic syndrome (SRNS) is a genetically heterogeneous disease with significant phenotypic variability. More than 53 podocyte-expressed genes are implicated in SRNS which complicates the routine use of genetic screening in the clinic. Next generation sequencing technology (NGS) allows rapid screening of multiple genes in large number of patients in a cost-effective manner.

Methods: We developed a targeted panel of 17 genes to determine relative frequency of mutations in south Indian ethnicity and feasibility of using the assay in a clinical setting. Twenty-five children with SRNS and 3 healthy individuals were screened.

Results: In this study, novel variants including 1 pathogenic variant (2 patients) and 3 likely pathogenic variants (3 patients) were identified. In addition, 2 novel variants of unknown significance (VUS) in 2 patients (8\% of total patients) were also identified.

Conclusions: The results show that genetic screening in SRNS using NGS is feasible in a clinical setting. However the panel needs to be screened in a larger cohort of children with SRNS in order to assess the utility of the customised targeted panel in Indian children with SRNS. Determining the prevalence of variants in Indian population and improvising the bioinformatics-based filtering strategy for a more accurate differentiation of pathogenic variants from those that are benign among the VUS will help in improving medical and genetic counselling in SRNS.
\end{abstract}

Keywords: SRNS, NGS, Targeted re-sequencing, Indian population

\section{Background}

Steroid resistant nephrotic syndrome (SRNS) remains one of the most common intractable causes of end-stage renal disease (ESRD) in children with $50-70 \%$ of these children developing end-stage renal disease within 5-10 years of diagnosis [1]. The therapeutic options in SRNS are often inefficient, and complicated by significant toxicity adding to the associated morbidities, mortality and cost. There is now compelling evidence that children with pathogenic variations in the genes responsible for maintenance of podocyte structure and function form a distinct subgroup of Nephrotic Syndrome (NS) and these children are

\footnotetext{
* Correspondence: anil.vasudevan@sjri.res.in; anilvasu@hotmail.com

${ }^{\dagger}$ Annes Siji, K. N. Karthik and Varsha Chhotusing Pardeshi contributed equally to this work.

'Division of Molecular Medicine, St. John's Research Institute, Bangalore, India ${ }^{2}$ Department of Pediatric Nephrology, St. John's Medical College Hospital, Bangalore, India
}

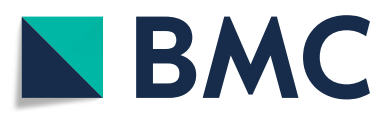

(c) The Author(s). 2018 Open Access This article is distributed under the terms of the Creative Commons Attribution 4.0 International License (http://creativecommons.org/licenses/by/4.0/), which permits unrestricted use, distribution, and reproduction in any medium, provided you give appropriate credit to the original author(s) and the source, provide a link to the Creative Commons license, and indicate if changes were made. The Creative Commons Public Domain Dedication waiver (http://creativecommons.org/publicdomain/zero/1.0/) applies to the data made available in this article, unless otherwise stated.

generally unresponsive to immunosuppression, but do not have post-transplantation recurrence $[2,3]$.

More than 53 single gene mutations specific to podocyte or associated with glomerular filtration barrier have been found to be associated with SRNS [4,5]. Large multi centric studies including population of multiple ethnicities showed genetic mutations in about $~ 30 \%$ of SRNS patients with a higher proportion in infants and young children. Most mutations were observed in NPHS2, WT1 and NPHS1 genes $[4,6]$.

However, reports from India including from our center showed that the prevalence of NPHS2 mutations is much lower in Indian population when compared with Europe and North American population [4\% vs. 10.528\%)] [7-12]. Kumar et al., reported low prevalence of WT1 mutation in south Indian population, whereas we did not detect any mutation in WT1 gene in 100 SRNS 
children [13, 14]. These data suggest that a traditional genetic testing using an algorithmic approach based on age of onset of NS to prioritize the genes to be sequenced by Sanger may not be useful $[15,16]$. The above data also indicates the need for additional screening of genes implicated in SRNS in order to understand the genetic spectrum of SRNS in Indian population. Given the genetic heterogeneity and phenotypic variability in SRNS, Sanger sequencing is not a feasible approach for routine testing. Next-generation sequencing (NGS) technology is emerging as a cost-effective strategy to screen multiple genes in genetically heterogeneous diseases like SRNS [17].

The aim of our study was to check the feasibility of genetic diagnosis using targeted next-generation sequencing (NGS) approach in Indian children with SRNS. We report the initial results along with the challenges faced in the analysis and interpretation of sequencing data obtained by simultaneously sequencing 17 genes in 25 children with SRNS and 3 healthy individuals.

\section{Methods}

\section{Subjects}

The Institutional Ethics Committee approved the study and all participants were recruited after informed consent. Twenty five children with idiopathic SRNS (18 males: 7 females) as defined by standard guidelines were included [18]. Socio demographic information, clinical and treatment details were recorded in case record forms. All these children were previously analyzed by Sanger sequencing for all the exons of NPHS2 and exon 8 and 9 of WT1 genes $[7,14]$.We also included three subjects with pathogenic mutations in NPHS2 reported previously to determine the sensitivity of the targeted-NGS method [7]. Three healthy individuals were included to check sequencing efficiency.

\section{Methods}

Blood samples $(5 \mathrm{ml})$ were collected from recruited patients and genomic DNA was extracted from peripheral blood leukocytes by the phenol chloroform method [19]. Quantity of the extracted DNA was estimated using Qubit fluorometric assay (Thermofisher scientific, MA, USA).

\section{Next-generation sequencing}

For targeted next-generation sequencing, we selected a panel of 17 genes associated with SRNS based on their prevalence in clinically diagnosed SRNS patients and mutation frequency in the NS cohorts (Table 1) $[4,5$, 20]. The genes selected for the panel accounted for 95$100 \%$ of the mutations in two large cohorts of SRNS one

Table 1 Genes included in the targeted NS panel to screen genetic variant in Indian SRNS cohort (to be placed after Page 5)

\begin{tabular}{|c|c|c|c|c|c|c|}
\hline Gene & Accession \# & Disease & Inheritance & $\begin{array}{l}\text { \# exons } \\
\text { covered }\end{array}$ & $\begin{array}{l}\text { \# exons not } \\
\text { covered }\end{array}$ & $\begin{array}{l}\text { \# primer } \\
\text { pairs }\end{array}$ \\
\hline$\overline{\mathrm{ACTN}^{\mathrm{a}}}$ & NM_004924 & Familial and sporadic SRNS (usually adult) & $A D$ & 21 & - & 25 \\
\hline ADCK4 & NM_024876 & SRNS & $A R$ & 13 & 1 & 15 \\
\hline CD2AP & NM_012120 & FSGS/SRNS & $A D / A R$ & 18 & - & 20 \\
\hline COQ2 & NM_015697 & Mitochondrial disease/isolated nephropathy & $A R$ & 7 & - & 9 \\
\hline COQ6 & NM_182476 & NS + sensorineural deafness; DMS & AR & 11 & 1 & 13 \\
\hline INF2 & NM_022489 & $\begin{array}{l}\text { Familial and sporadic SRNS, FSGS-associated Charcot-Marie-Tooth } \\
\text { neuropathy }\end{array}$ & $A D$ & 22 & 1 & 37 \\
\hline LAMB2 & NM_002292 & Pierson syndrome & $A R$ & 32 & 1 & 35 \\
\hline$L M X 1 B$ & NM_002316 & Nail patella syndrome; also FSGS without extrarenal involvement & $A D$ & 8 & 2 & 13 \\
\hline MYO1E & NM_004998 & Familial SRNS & $A R$ & 28 & - & 28 \\
\hline NEIL1 & NM_024608 & childhood SRNS & AR & 11 & - & 12 \\
\hline NPHS1 & NM_004646 & CNS/SRNS & $A R$ & 29 & - & 32 \\
\hline $\mathrm{NPHS2^{ \textrm {a } }}$ & NM_014625 & CNS, SRNS & $A R$ & 8 & - & 10 \\
\hline PDSS2 & NM_020381 & Leigh syndrome & $A R$ & 8 & - & 9 \\
\hline $\mathrm{PLCe}^{\mathrm{a}}$ & NM_016341 & CNS/SRNS & $A R$ & 32 & - & 42 \\
\hline PTPRO & NM_030667 & NS & $A R$ & 25 & 2 & 28 \\
\hline TRPC6 & NM_004621 & Familial and sporadic SRNS (mainly adult) & $A D$ & 13 & & 18 \\
\hline WT1 & NM_024426 & $\begin{array}{l}\text { Sporadic SRNS (children: may be associated with abnormal genitalia); } \\
\text { Denys-Drash and Frasier syndrome }\end{array}$ & $A D$ & 10 & - & 13 \\
\hline
\end{tabular}

$A D$ autosomal dominant, $A R$ autosomal recessive, DMS diffuse mesangial sclerosis, ESRD end-stage renal disease, FSGS focal segmental glomerulosclerosis, NS

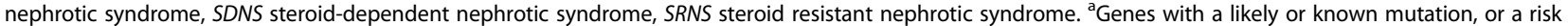
allele, in this cohort 
of which included Indian children [6,21]. A total of 359 primers targeting the exonic regions of the selected 17 genes (307 exons) associated with nephrotic syndrome were designed using Ion Ampliseq Designer (Life Technologies, CA, USA). The amplicon size was designed in a range from 125 to $375 \mathrm{bp}$. The panel consisted of three primer pools amplicon size ranging from 125 to $375 \mathrm{bp}$ and covering $99.6 \%$ exon of the selected genes. The uncovered region was mainly repeat rich region making primer designing difficult. An Ion Torrent adapter-ligated library was prepared using the Ion AmpliSeq Library Kit 2.0 (Life Technologies, CA, USA) by following the manufacturer's protocol. Briefly, $10 \mathrm{ng}$ of DNA was amplified by PCR using the premixed primer pool and Ion AmpliSeq HiFi master mix. After PCR, the amplified targets were treated with FuPa reagent to partially digest primer sequences and phosphorylate the amplicons. For adaptor ligation, amplicons from each sample were combined with a barcode adapter mix that contained Ion P1 adaptor and a unique Ion Xpress Barcode (Life Technologies, CA, USA). The unamplified libraries were purified using AMPure beads (Beckman Coulter, CA, USA) and the purified beads were amplified using Platinum PCR SuperMix High Fidelity and Library Amplification Primer Mix (Life Technologies, CA, USA). The amplified library was purified using AMPure beads. Library quantity and quality was determined using Qubit fluorometric assay and Agilent BioAnalyzer High-Sensitivity DNA kit (Agilent Technologies, CA, USA), respectively.

Template preparation, emulsion PCR, and Ion Sphere Particles (ISP) enrichment were done using the Ion PGM Template OT2 400 kit (Life Technologies, CA, USA) according to the manufacturer's instructions. Next-generation sequencing was carried out on Ion Torrent Personal Genome Machine sequencer (Life Technologies, CA, USA) using the Ion 318 and 314 Chips (Life Technologies, CA, USA) and Ion PGM Hi-Q Sequencing Kit (Life Technologies, CA, USA) according to the manufacturer's instructions.

\section{Variant calling and annotation}

The data from the both sequencing runs were analyzed using the Torrent Suite V5 analysis pipeline. Sequence reads were separated according to their barcodes. Human genome sequence (build GRCh37/hg19) was used as a reference sequence. For each individual barcode, the sequence reads were aligned to this reference sequence with a Torrent Mapping Alignment Program optimized to Ion torrent data using the default alignment algorithm and parameters. After alignment, the variants were annotated to determine their clinical significance by using a combination of frequency, structural prediction, or evidence- based data. The DNA variant regions were piled up with Torrent Variant Caller (TVC) plug-in software to identify missense, nonsense, frameshift, obligatory splice variants and short insertion/deletion (indels) across the targeted subset of the reference using germ-line parameters and low stringency settings. The output variant call format (VCF) file was then annotated using Ion Reporter Software v5.0 (Life Technologies, CA, USA) and variants were further investigated. All the variants were filtered based on their coverage (coverage $>30$ ), variant effect (non-synonymous, frameshift, nonsense), location (to detect splice site variants) and allele frequency in public databases (ExAc (http://exac.broadinstitute.org/), and 5000 Exome (http://evs.gs.washington.edu/EVS/) $<1 \%$ ). The filtered variants were visually examined using Integrative Genomics Viewer (IGV) software (http//www.broadinstitute.org/igv), to further filter out variants with possible strand-bias and variants within homopolymeric region. In silico analysis using Sorting Tolerant From Intolerant (SIFT) and Polymorphism Phenotyping v2 (Polyphen-2) tools was performed to predict the potential deleterious effect of the identified missense variants on protein function [22, 23]. Bioinformatics analysis of the strength of predicted splice site variants was performed with neural networks (NNSPLICE 0.9) [24]. The variants were classified as pathogenic, likely pathogenic, uncertain significance, likely benign, or benign according to the stringent criteria of American College of Medical Genetics and Genomics (ACMG) Standards and Guidelines and Sherloc rules $[25,26]$. A scoring system developed by Karbassi et al. was used to determine the pathogenicity of VUS identified in this study [27].

The pathogenic and likely pathogenic variants were validated by Sanger sequencing using variant specific primers in patients as well as in healthy individuals $(n=30)$ (Additional file 1: Table S1).

\section{Results}

\section{Demographic and clinical profile}

The clinical details of 25 SRNS patients are presented in Table 2 with detailed phenotyping in Additional file 1: Table S2. The median age of onset of NS was 2.5 years(0.58-16 years) with a median follow up of 2.5 years. Majority of the patients were non-responsive to non steroidal immunosuppressant, with only 8 children demonstrating partial response to calcineurin inhibitors (Additional file 1: Table S2).

\section{Sequencing results}

Two sequencing runs, containing 25 samples (23 patients and 2 healthy individual sample; 318 chip) and 4 samples (2 patients, 1 healthy individual sample and one human standard CEPH DNA sample; 314 chip) were performed. 
Table 2 Clinical characteristics of the South Indian nephrotic syndrome cohort

\begin{tabular}{|c|c|c|}
\hline \multicolumn{2}{|l|}{ Characteristics } & \multirow{2}{*}{$\begin{array}{l}\text { Total }(n=25)(\%) \\
18(72)\end{array}$} \\
\hline Sex & Male & \\
\hline & Female & $7(28)$ \\
\hline \multirow[t]{5}{*}{ Age at diagnosis } & Median (years) & 2.5 years \\
\hline & Infantile (4-12 months) & $3(12)$ \\
\hline & Early childhood (13 months -5 years) & $16(64)$ \\
\hline & Late childhood (6-12 years) & $4(16)$ \\
\hline & Adolescent (13-18 years) & $2(8)$ \\
\hline \multirow[t]{2}{*}{ Family history } & Yes & $7(28)$ \\
\hline & No & $18(72)$ \\
\hline \multirow[t]{2}{*}{ Parental consanguinity } & Yes & $5(20)$ \\
\hline & No & $20(80)$ \\
\hline \multirow[t]{2}{*}{ Steroid resistance } & primary steroid resistance & $24(96)$ \\
\hline & Secondary steroid resistance & $1(4)$ \\
\hline \multirow[t]{5}{*}{ Histopathology subtype } & Focal segmental glomerulosclerosis (FSGS) & $14(56)$ \\
\hline & Minimal change disease (MCD) & $3(12)$ \\
\hline & Mesangial hypercellularity (MHC) & $6(24)$ \\
\hline & Diffuse mesangial sclerosis (DMS) & $1(4)$ \\
\hline & Unknown & $1(4)$ \\
\hline \multirow[t]{6}{*}{ Renal outcome } & Remission & $2(8)$ \\
\hline & Persistent relapse & $9(36)$ \\
\hline & Chronic Kidney disease Stage II-IV & $4(16)$ \\
\hline & End stage renal disease & $5(20)$ \\
\hline & Underwent renal transplant & $1(4)$ \\
\hline & Dead & $4(16)$ \\
\hline
\end{tabular}

Total $854 \mathrm{M}(\mathrm{Q} 20)$ and $172 \mathrm{M}$ of Q20 data were obtained per 318 and 314 chips respectively and the coverage was comparable between runs. After filtering out polyclonal, low quality reads, and primer-dimers, the percentage of usable reads were $4.57 \mathrm{M}$ and $0.788 \mathrm{M}$ per 318 and 314 chips respectively (Additional file 1: Table S3). Combining the data derived from two runs, sequencing of the 17 glomerular disease gene panel generated a mean of $0.18 \mathrm{M}$ reads per individual with mean read length of $214 \mathrm{bp}$. Only $10 \%$ of called bases had a quality score of $<$ Q20; About $99 \%$ of these reads were mapped to the reference genome (hg19) and 93.9\% of mapped reads were on target genes (Additional file 1: Table S4). A mean coverage of $442 \times$ was achieved for the genes across all individuals, with $93.1,63.2$ and $17 \%$ of the targets having minimum read depth of $20 \times, 100 \times$ and $500 \times$ respectively.

Overall, 2916 single-nucleotide variants (SNVs) and indels were identified in the 25 patients and 3 healthy individuals by Torrent Suite software V5, using default germline parameters. These variants were annotated and filtered using the Ion Reporter Software 4.4 with following parameters: inclusion of frameshift, stop loss, missense, nonsense variants and variants located in splice site with a minimum coverage of $20 \times$. After the filtration, a total of 26 variants (23 missense, 2 nonsense and 1 splice site) were identified in 13 genes in 16 subjects (Fig. 1). Among these variants, 1 pathogenic NPSH2 (R71X), 3 likely pathogenic [PLCe1 (R752X), NPHS1 (G968 V) and NPHS2 (splice site variant, g $.179521737 \mathrm{C}>\mathrm{T})]$ and 2 VUS (LMX1B (V145 M) and NPHS2 (H141Y) were considered clinically relevant. The remaining 20 variants not considered further for annotation included 15 heterozygous VUS in genes with recessive inheritance, two VUS (P973T and P995L) in MYO1E gene in a single patient (SRNS 60) in cis and a likely benign variant (R877Q) in INF2 gene. A homozygous VUS in PLCe1 (G222R) gene in SRNS was also excluded from further annotation, as it was observed in a healthy individual. A variant in ACTN4 gene (R310Q) was excluded from clinically relevant list although it was classified as likely pathogenic based on ACMG criteria. This variant has a very low allele frequency in ExAC database and also has been reported in probands of families with FSGS and individuals with sporadic FSGS [0.0074 (8/ 1084) controls 0.016 (3/192) sporadic FSGS] [28]. Besides, podocyte transient transfection assay indicates that the mutation inhibited the complex formation between $\alpha$-actinin- 4 


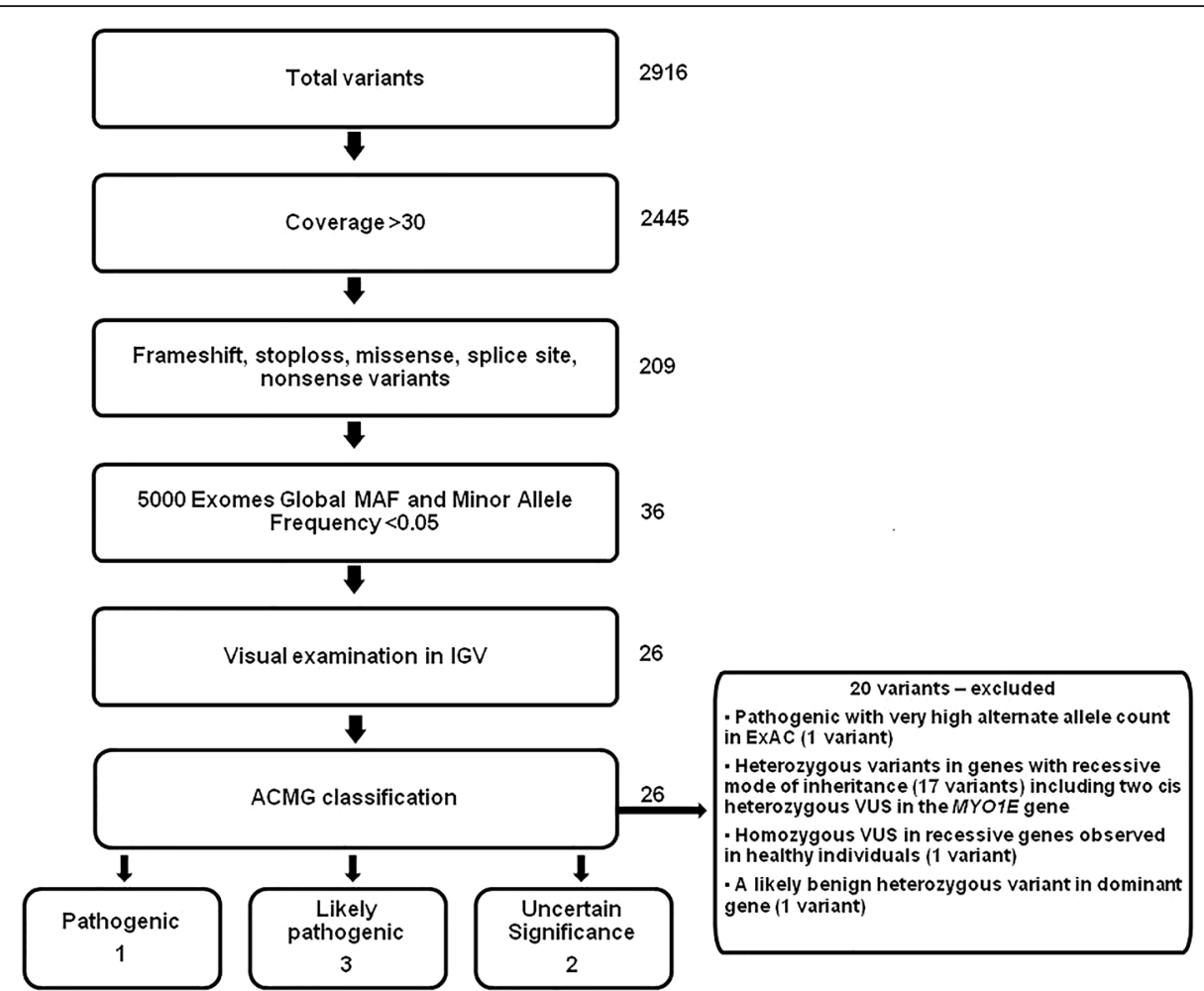

Fig. 1 Flow chart of next generation sequencing variant filtration and annotation. The variants were filtered based on their coverage (minimum coverage of 20x), variant effect, dbSNP, ExAC, 500 exomes and 1000 Genome Project databases status. The filtered variants were visually examined using Integrative Genomics Viewer (IGV) software (http//www.broadinstitute.org/igv), to further filter out variants with possible strand-bias and variants that fall into homopolymeric region. All the filtered variants were annotated as per the ACMG guidelines

and CLP36 causing the podocyte defect although the precise pathways involved were not identified [29]. However, a large number of alternate alleles $(n=$ 1426) have been identified at the same position in general population Although global allele frequency of p.R310Q variant in ACTN4 was $<1 \%$, total allele count was higher (3138) in gnomAD database (Updated version of ExAC, http://gnomad.broadinstitute.org/variant/19-39207742-G-A). As per the Sherloc rule (EV0161, https://www.ncbi.nlm.nih.gov/pubmed/ 28492532), variants with allele count $>8$, is considered as high allele count and the variant is classified as benign. Therefore although the based on the ACMG criteria p.R310Q variant in ACTN4 was classified as pathogenic, it was considered as benign based on the improved and robust variant classification guidelines of Sherloc.

The pathogenic variant in NPSH2 (R71X) gene was observed in a pair of sibling (8\%). The likely pathogenic variants in PLCe1 (R752X), NPHS1 (G968 V) and NPHS2 (splice site variant, g .179521737C $>\mathrm{T}$ ) genes were identified in one subject each (4\%) (Table 3). All these variants were novel except for the NPHS2 variant (R71X) [30]. Of the 2 variants, identified by Sangers sequencing previously, one variant $(\mathrm{H} 141 \mathrm{Y})$ was not present in the final filtered variants. A review of the NGS data indicated that the variant was identified by the sequencing but was filtered because of the stringent variant filtration settings (minimum read depth of 30x). A total of 18 reads was obtained for this variant $\mathrm{H} 141 \mathrm{Y}$ in NPHS2. The pathogenic and likely pathogenic variants were validated using Sanger sequencing in the respective patients and 30 healthy individual samples and no false positives were identified. The pathogenicity score of two variants (LMX1B; heterozygous, V145 M, andNPHS2; homozygous, H141Y) classified as variants of uncertain significance (VUS) indicated that they could be pathogenic in nature and needed to be explored further for their causality in SRNS (Additional file 1: Table S5).

\section{Genotype -phenotype correlation of disease-causing variants in the cohort}

The clinical features and the renal histology were similar between those with pathogenic or likely pathogenic variants. Response to immunosuppressive treatments was not significantly different between those with pathogenic or likely pathogenic variants and those without an abnormal variant. The homozygous nonsense R71X variant in NPHS2 gene was identified in two siblings (patient SRNS20 and SRNS76). The siblings presented with NS at age of 3.5 and 2.5 years respectively and both showed FSGS on biopsy. Both subjects showed no response to 


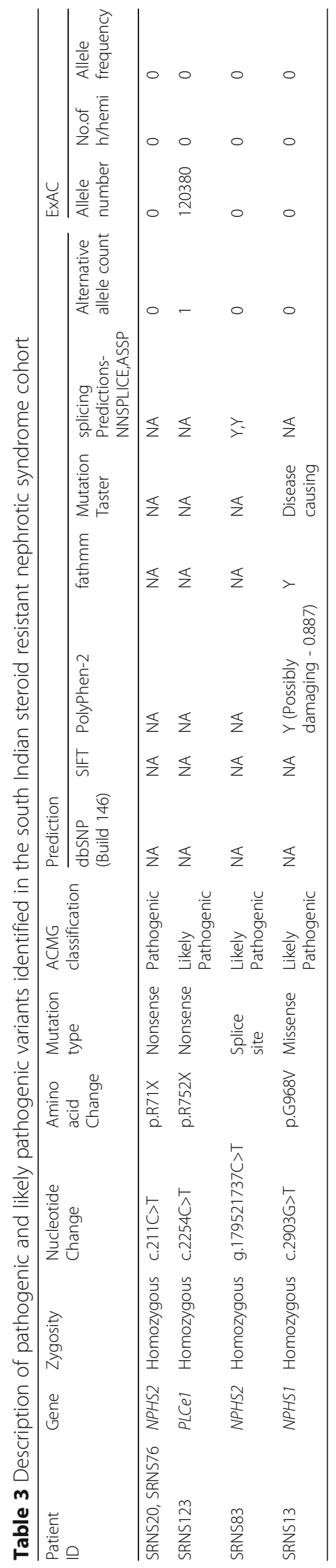


calcineurin inhibitors. The elder sibling (patient SRNS20) progressed to ESRD by the age of 5 years and died at the age of 6 years with sepsis. The younger sibling currently aged 4.5 years (patient SRNS76) is in CKD stage 3 (Additional file 1: Table S2). Their parents were heterozygous for the point mutation (data not shown). A likely pathogenic homozygous nonsense variant $\mathrm{R} 752 \mathrm{X}$ in $P L C e 1$ gene was identified in SRNS123 in whom renal biopsy showed DMS (Additional file 1: Table S3). This child presented with symptoms of NS at the age of 1.5 years had renal dysfunction at the time of diagnosis and progressed to ESRD within a year of diagnosis. Similar histopathology has been reported with pathogenic variants in $P L C e 1$ gene [31]. A splice site likely pathogenic variant was observed in NPHS2 gene in patient 83 who also had a homozygous VUS in the same gene (H141Y missense, both parents are heterozygous for this particular variant). This child manifested SRNS at the age of 1.2 years, showed FSGS on renal biopsy and progressed to ESRD, 2 years after diagnosis. SRNS 13 was identified to have the homozygous recessive variant $(\mathrm{G} 968 \mathrm{~V})$ in the NPHS1 gene. The child was diagnosed as SRNS at age of 10 months, with the biopsy report revealing $\mathrm{MHC}$ and is in remission at last follow up. Patient 73 in whom a heterozygous variant in $L M X 1 B$ (dominant inheritance) was observed manifested SRNS at the age of 3.5 years with FSGS on biopsy and progressed to ESRD within 7 years of diagnosis. The risk score suggests pathogenicity.

\section{Discussion}

Identifying the cause of SRNS is of great importance as it helps in preventing unnecessary exposure to immunosuppressants and their adverse effects, besides establishing a molecular diagnosis and clear prognosis. It also enables targeted treatment as in case of children with pathogenic variants identified in gene encoding enzymes of the co-enzyme Q 10 biosynthesis who are amenable to treatment with coenzyme Q 10 [32].

We report the results of sequencing for molecular diagnosis of SRNS in Indian children by screening 17 genes wherein pathogenic variant in NPHS2 gene was identified in $8 \%$ patients. Siblings carrying this variant along with the patient 83 carrying the NPHS2 variant H141Y were included as positive samples to check the sensitivity of the present assay. Both these variants were detected (although variant H141Y was initially missed due to low read depth) and no spurious pathogenic mutations were found in any of these samples indicating $85 \%$ sensitivity for the assay. Beside these known variants, 3 novel likely pathogenic variants were identified in 3 patients (12\%) who were previously sequenced for NPHS2 and WT1 genes. These findings demonstrate the utility of NGS in a clinical setting since it allows for rapid and simultaneous screening of multiple SRNS associated genes instead of prioritizing specific genes for genetic testing.

The targeted gene panel was developed based on the results from two largest SRNS cohorts one of which included Indian children with SRNS. The targeted panel included 17 genes which explained the genetic basis in $>95 \%$ of children with SRNS in these two cohorts. Previous studies using the targeted multi-gene sequencing to analyze the exon and intron boundaries of genes associated with SRNS in various populations identified mutations in $\sim 30 \%$ of the patients [4-6, 21, 33-37]. In the present study, disease causing variants were identified in $20 \%$ of the cohort which is lesser than that expected probably due to small number of patients included in the cohort.

The most common disease causing variants were identified in the NPHS2, WT1, and NPHS1 genes in the Podonet cohort (1174 patients from 21 countries; included 9 Indian patients $=0.7 \%$ ), in 1783 unrelated, multinational cohort and in the UK cohort [21]. This in contrast to the Chinese population, wherein the disease causing variants were also identified in $A D C K 4$ gene (6.67\%), in addition to NPHS1, WT1, and NPHS2 genes [37]. In the present study, although the cohort size was small, disease causing variants were identified in NPHS2 (12\%) NPHS1 (4\%) and PLCe1 (4\%) genes indicating that the genes with variants causing SRNS varies significantly according to ethnic background. While this study and our previous study indicate that NPHS2 gene is the most common mutated gene in Indian population [7], we also identified NPHS1 and PLCe1 genes mutations that would not have been considered in the conventional genetic testing algorithms for SRNS using Sanger sequencing.

All the pathogenic variants were identified in genes associated with recessive Mendelian inheritance, as most of the children (64\%) in the cohort developed SRNS at an early age ( $<5$ years). The age of onset in our study correlated with risk for an as reported in other studies $[6,16]$. Surprisingly, we did not find any pathogenic variants in infantile group. This is contrast to the findings from other studies where in $\sim 66.3 \%$ of SRNS cases (onset between 0 and 1 year) is due to the mutation in one of following four genes: NPHS1, NPHS2, LAMB2, or WT1 [38]. This indicates that additional SRNS associated genes needs to be screened in this group.

It is well known that SRNS exhibits significant inter and intra familial variability. The use of NGS allows to study the influence of disease causing variants in multiple genes on phenotype variability [33]. In the present cohort, two siblings with identical pathogenic variant (NPHS2 R71X; SRNS20 and SRNS76) showed different 
clinical course. The variability in the clinical phenotype of patients carrying the same variant indicate an environmental factor or a possible second-site genetic modification, whereby pathogenic variants in a second gene might modulate the penetrance and/or expressivity of recessive mutations in a primary locus. Although in the siblings we did identify additional variant (R408Q) in NPHS1, it was heterozygous and classified as begnin by both ACMG and Karbassi et al. variant scoring system $[25,27]$. In patient 83 , two variants in the NPHS2 gene (splice site, g.179521737C $>\mathrm{T}$ and missense H141Y) were identified. The splice site variant was classified as likely pathogenic while the $\mathrm{H} 141 \mathrm{Y}$ variant was classified as VUS, with the risk score suggesting pathogenic nature. It is difficult to predict which variant is contributing to the disease development in this child. In order determine the role of multiple variants on the phenotypic variability we need to compare patients with different genotype combinations in the various cohorts that have been studied.

The main barrier to determine the pathogenicity of a variant is absence or limited functional testing of variants discovered to identify specific variants that results in dysfunction of the protein product. For example, a novel homozygous variant R752X, in PLCe1 gene in patient 123 was classified as likely pathogenic instead of pathogenic. Based on the clinical findings and histopathology of patient 123, it is evident that PLCe1 gene variant can potentially be attributed to the disease development in this patient. However, lack of data which would help with the segregation of alleles in cases and the reference population and absence of functional data, we were unable to classify this variant as pathogenic.

Secondly, guidelines to annotate the heterozygous variants in dominant genes are not very clear. For example the novel $L M X 1 B$ gene variant V145 M with low allele frequency was predicted to be pathogenic in nature as per the Karbassi scoring algorithm but still classified as VUS as per the ACMG criteria. Further functional studies are required to confirm the effect of this variant on protein function and disease phenotype. Since little robust data is available upon which to base an assessment of causality in case of VUS, reporting, genetic and medical counseling can be complex and challenging. There is no consensus on optimal strategies to report such findings and for clinician to communicate them with parents. Counselling parents with an affected child with a VUS is even more challenging in a prenatal setting as quantifying the attributable risk of developing the disease is not possible if the variant is prospectively detected in the unborn fetus. Hence developing appropriate and effective clinical approaches to this challenge including additional training to clinicians in pretest counseling and consenting, interpretation of results and communication of results to the parents is essential. Besides, integrating the data from this study with large publically accessible phenotype and genotype data may help in ascertaining the role of novel variants in disease development and also determine the role of multiple variants on the phenotypic variability.

This study is unique as it is the first Indian study using well phenotyped SRNS cohort and NGS technology for the genetic diagnosis of SRNS. However it had few limitations such as non-random sample selection (majority of the patients were early childhood onset) and selection of small number of patients from a single center. As parental DNA was not available we could not perform segregation studies in the familial cases except in one family.

\section{Conclusions}

In conclusion, we demonstrated the feasibility of genetic screening using a targeted gene panel in a clinical setting. However, a larger number of children with SRNS needs to be screened in order to know the genetic profile as well as determine the utility of customizing targeted gene panel to screen Indian children with SRNS. Such screening will help the clinician in better prognostication and rationalizing treatment of SRNS patients. However, there were challenges in the interpretation of variants and uncertainty of some results. Improving bioinformatics-based filtering strategy will help in differentiating pathogenic variants from those that are benign among VUS.

\section{Additional file}

Additional file 1: Table S1. Details of primers used for Sanger sequencing to validate the variants identified by next generation sequencing. Table S2. Detailed Clinical profile of the South Indian steroid resistant nephrotic syndrome cohort. Table S3. Ion PGM next-Generation Sequencing run summary. Table S4. Summary of per sample NGS data output and quality in Indian steroid resistant Nephrotic syndrome cohort. Table S5. Pathogenicity risk score of the Variant of unknown significance (VUS) (XLSX $25 \mathrm{~kb})$

\section{Abbreviations}

ACMG: American college of medical genetics; CEPH: Centre d'Etude du polymorphisme; CKD: Chronic kidney disease; DMS: Diffuse mesiangial sclerosis; DNA: Deoxyribo nucleic acid; ESRD: End stage renal disease;

FSGS: Focal segmental glomerulosclerosis; IGV: Integrative genomics viewer; ISP: Ion sphere particles; MCD: Minimal change disease; MHC: Mesiangial hypercellularity; NGS: Next generation sequencing; NS: Nephrotic syndrome; SIFT: Sorting tolerant from intolerant; SNV: Single nucleotide variant; SRNS: Steroid resistant nephrotic syndrome; TVC: Torrent variant calling; VCF: Variant call format; VUS: Variants of unknown significance

\section{Acknowledgements}

We thank all the patients who participated in the study.

\section{Funding}

This work was supported by a grant TATA Educational Trust (Health-CKCC20141118). We also acknowledge Indian Council of Medical Research (3/ 1/ 2/ 6-RCH; IRIS ID No.2012-26950) for their support. 


\section{Availability of data and materials}

The data supporting the results of this article are included within the article and in its additional files.

\section{Authors' contributions}

AS was involved in patient recruitment, sample collection and performed the DNA extraction, involved in NGS library preparation and Sequencing. KKN involved in NGS library preparation, sequencing and NGS data analysis. HPS involved in NGS data analysis. VCP involved in NGS sample preparation, QC, sequencing, data analysis and manuscript preparation. AV originated the study, panel gene selection and design, reviewed data analysis and co-wrote the manuscript. All authors read and approved the final manuscript.

\section{Ethics approval and consent to participate}

The Institutional Ethics Committee, St. John's Medical College, Bangalore, India, approved the study and all participants were recruited after informed consent. The approval number for the study was 171/ 2012. Parents of the children (under the age of 16) consented to participate in the study.

\section{Consent for publication}

Not applicable.

\section{Competing interests}

The authors declare that they have no competing interest.

\section{Publisher's Note}

Springer Nature remains neutral with regard to jurisdictional claims in published maps and institutional affiliations.

Received: 8 July 2018 Accepted: 7 November 2018 Published online: 20 November 2018

\section{References}

1. Mekahli D, Liutkus A, Ranchin B, Yu A, Bessenay L, Girardin E, Van Damme-Lombaerts R, Palcoux J-B, Cachat F, Lavocat M-P, BourdatMichel G, Nobili F, Cochat P. Long-term outcome of idiopathic steroid-resistant nephrotic syndrome: a multicenter study. Pediatr Nephrol. 2009;24:1525-32.

2. Ding WY, Koziell A, McCarthy HJ, Bierzynska A, Bhagavatula MK, Dudley JA, Inward CD, Coward RJ, Tizard J, Reid C, Antignac C, Boyer O, Saleem MA. Initial steroid sensitivity in children with steroid-resistant nephrotic syndrome predicts post-transplant recurrence. J Am Soc Nephrol. 2014:25:1342-8.

3. Bierzynska A, Saleem MA. Deriving and understanding the risk of posttransplant recurrence of nephrotic syndrome in the light of current molecular and genetic advances. Pediatr Nephrol. 2017;33(11):2027-2035

4. Bierzynska A, McCarthy HJ, Soderquest K, Sen ES, Colby E, Ding WY, Nabhan MM, Kerecuk L, Hegde S, Hughes D, Marks S, Feather S, Jones C, Webb NJA, Ognjanovic M, Christian M, Gilbert RD, Sinha MD, Lord GM, Simpson M, Koziell AB, Welsh GI, Saleem MA. Genomic and clinical profiling of a national nephrotic syndrome cohort advocates a precision medicine approach to disease management. Kidney Int. 2017;94:884-90.

5. Sen ES, Dean P, Yarram-Smith L, Bierzynska A, Woodward G, Buxton C, Dennis G, Welsh Gl, Williams M, Saleem MA. Clinical genetic testing using a custom-designed steroid-resistant nephrotic syndrome gene panel: analysis and recommendations. J Med Genet. 2017;54(12):795-804. https://doi.org/ 10.1136/jmedgenet-2017-104811.

6. Sadowski CE, Lovric S, Ashraf S, Pabst WL, Gee HY, Kohl S, Engelmann S, Vega-Warner V, Fang H, Halbritter J, Somers MJ, Tan W, Shril S, Fessi I, Lifton RP, Bockenhauer D, El-Desoky S, Kari JA, Zenker M, Kemper MJ, Mueller D, Fathy HM, Soliman NA, Hildebrandt F. A single-gene cause in $29.5 \%$ of cases of steroid-resistant nephrotic syndrome. J Am Soc Nephrol. 2015; 26:1279-89

7. Vasudevan A, Siji A, Raghavendra A, Sridhar TS, Phadke KD. NPHS2 mutations in Indian children with sporadic early steroid resistant nephrotic syndrome. Indian Pediatr. 2012;49(3):231-3.

8. Weber S, Gribouval O, Esquivel EL, Morinière V, Tête M-J, Legendre C, Niaudet P, Antignac C. NPHS2 mutation analysis shows genetic heterogeneityof steroid-resistant nephrotic syndrome and lowposttransplant recurrence. Kidney Int. 2004;66:571-9.
9. Ruf RG, Lichtenberger A, Karle SM, Haas JP, Anacleto FE, Schultheiss M, Zalewski I, Imm A, Ruf E-M, Mucha B, Bagga A, Neuhaus T, Fuchshuber A, Bakkaloglu A, Hildebrandt F, Arbeitsgemeinschaft Für Pädiatrische Nephrologie Study Group. Patients with mutations in NPHS2 (podocin) do not respond to standard steroid treatment of nephrotic syndrome. J Am Soc Nephrol. 2004;15:722-32.

10. Karle SM, Uetz B, Ronner V, Glaeser L, Hildebrandt F, Fuchshuber A. Novel mutations in NPHS2 detected in both familial and sporadic steroid-resistant nephrotic syndrome. J Am Soc Nephrol. 2002;13:388-93.

11. Caridi G. Broadening the Spectrum of diseases related to Podocin mutations. J Am Soc Nephrol. 2003;14:1278-86.

12. Caridi G, Bertelli R, Carrea A, Di Duca M, Catarsi P, Artero M, Carraro M, Zennaro C, Candiano G, Musante L, Seri M, Ginevri F, Perfumo F, Ghiggeri GM. Prevalence, genetics, and clinical features of patients carrying podocin mutations in steroid-resistant nonfamilial focal segmental glomerulosclerosis. J Am Soc Nephrol. 2001;12:2742-6.

13. Kumar AS, Srilakshmi R, Karthickeyan S, Balakrishnan K, Padmaraj R, Senguttuvan P. Wilms' tumour 1 gene mutations in south Indian children with steroid-resistant nephrotic syndrome. Indian J Med Res. 2016;144:276-80.

14. Siji A, Pardeshi VC, Ravindran S, Vasudevan A, Vasudevan A. Screening of WT1 mutations in exon 8 and 9 in children with steroid resistant nephrotic syndrome from a single Centre and establishment of a rapid screening assay using high-resolution melting analysis in a clinical setting. BMC Med Genet. 2017;18:3.

15. Benoit G, Machuca E, Antignac C. Hereditary nephrotic syndrome: a systematic approach for genetic testing and a review of associated podocyte gene mutations. Pediatr Nephrol. 2010;25:1621-32.

16. Santin S, Bullich G, Tazon-Vega B, Garcia-Maset R, Gimenez I, Silva I, Ruiz P, Ballarin J, Torra R, Ars E, Ikeda M, Honda M, lijima K. Clinical utility of genetic testing in children and adults with steroid-resistant nephrotic syndrome. Clin J Am Soc Nephrol. 2011;6:1139-48.

17. Drmanac R. The advent of personal genome sequencing. Genet Med. 2011; 13:188-90.

18. Gulati A, Bagga A, Gulati S, Mehta KP, Vijayakumar M. Management of steroid resistant nephrotic syndrome. Indian Pediatr. 2009;46:35-47.

19. Miller SA, Dykes DD, Polesky HF. A simple salting out procedure for extracting DNA from human nucleated cells. Nucleic Acids Res. 1988;16:1215.

20. Brown EJ, Pollak MR, Barua M. Genetic testing for nephrotic syndrome and FSGS in the era of next-generation sequencing. Kidney Int. 2014;85:1030-8.

21. Trautmann A, Bodria M, Ozaltin F, Gheisari A, Melk A, Azocar M, Anarat A, Caliskan S, Emma F, Gellermann J, Oh J, Baskin E, Ksiazek J, Remuzzi G, Erdogan O, Akman S, Dusek J, Davitaia T, Ozkaya O, Papachristou F, FirsztAdamczyk A, Urasinski T, Testa S, Krmar RT, Hyla-Klekot L, Pasini A, Ozcakar ZB, Sallay P, Cakar N, Galanti M, et al. Spectrum of steroid-resistant and congenital nephrotic syndrome in children: the PodoNet registry cohort. Clin J Am Soc Nephrol. 2015;10:592-600.

22. Ng PC, Henikoff S. SIFT: predicting amino acid changes that affect protein function. Nucleic Acids Res. 2003;31:3812-4.

23. Adzhubei I, Jordan DM, Sunyaev SR. Predicting functional effect of human missense mutations using PolyPhen-2. Current protocols in human genetics. Volume chapter 7. Hoboken, NJ: John Wiley \& Sons, Inc;; 2013. 7.20.1-7.20.41

24. REESE MG, EECKMAN FH, KULP D, HAUSSLER D. Improved splice site detection in genie. J Comput Biol. 1997:4:311-23.

25. Richards CS, Bale S, Bellissimo DB, Das S, Grody WW, Hegde MR, Lyon E, Ward BE. ACMG recommendations for standards for interpretation and reporting of sequence variations: revisions 2007. Genet Med. 2008;10:294-300.

26. Nykamp K, Anderson M, Powers M, Garcia J, Herrera B, Ho Y-Y, Kobayashi Y, Patil N, Thusberg J, Westbrook M, Topper S, Topper S. Sherloc: a comprehensive refinement of the ACMG-AMP variant classification criteria. Genet Med. 2017;19:1105-17.

27. Karbassi I, Maston GA, Love A, DiVincenzo C, Braastad CD, Elzinga CD, Bright AR, Previte D, Zhang K, Rowland CM, McCarthy M, Lapierre JL, Dubois F, Medeiros KA, Batish SD, Jones J, Liaquat K, Hoffman CA, Jaremko M, Wang Z, Sun W, Buller-Burckle A, Strom CM, Keiles SB, Higgins JJ. A standardized DNA variant scoring system for pathogenicity assessments in Mendelian disorders. Hum Mutat. 2016;37:127-34.

28. Weins A, Kenlan P, Herbert S, Le TC, Villegas I, Kaplan BS, Appel GB, Pollak MR. Mutational and biological analysis of alpha-actinin-4 in focal segmental glomerulosclerosis. J Am Soc Nephrol. 2005;16:3694-701.

29. Liu Z, Blattner SM, Tu Y, Tisherman R, Wang JH, Rastaldi MP, Kretzler M, Wu C. Alpha-actinin-4 and CLP36 protein deficiencies contribute to podocyte 
defects in multiple human glomerulopathies. J Biol Chem. 2011;286: 30795-805.

30. Sun $H$, Zhou W, Wang J, Yin L, Lu Y, Fu Q. A novel mutation in NPHS2 gene identified in a Chinese pedigree with autosomal recessive steroid-resistant nephrotic syndrome. Pathology. 2009;41:661-5.

31. Machuca E, Benoit G, Nevo F, Tete M-J, Gribouval O, Pawtowski A, Brandstrom P, Loirat C, Niaudet P, Gubler M-C, Antignac C. Genotypephenotype correlations in non-Finnish congenital nephrotic syndrome. J Am Soc Nephrol. 2010;21:1209-17.

32. Heeringa SF, Chernin G, Chaki M, Zhou W, Sloan AJ, Ji Z, Xie LX, Salviati L, Hurd TW, Vega-Warner V, Killen PD, Raphael Y, Ashraf S, Ovunc B, Schoeb DS, McLaughlin HM, Airik R, Vlangos CN, Gbadegesin R, Hinkes B, Saisawat P, Trevisson E, Doimo M, Casarin A, Pertegato V, Giorgi G, Prokisch H, Rötig A, Nürnberg G, Becker C, et al. COQ6 mutations in human patients produce nephrotic syndrome with sensorineural deafness. J Clin Invest. 2011; 121:2013-24.

33. Bullich $G$, Trujillano D, Santín S, Ossowski S, Mendizábal S, Fraga G, Madrid Á, Ariceta G, Ballarín J, Torra R, Estivill X, Ars E. Targeted next-generation sequencing in steroid-resistant nephrotic syndrome: mutations in multiple glomerular genes may influence disease severity. Eur J Hum Genet. 2014;23: 1192 Publ online 19 Novemb 2014; | doi101038/ejhg2014252.

34. Crawford BD, Gillies CE, Robertson CC, Kretzler M, Otto E, Vega-Wagner V, Sampson MG. Evaluating Mendelian nephrotic syndrome genes for evidence for risk alleles or oligogenicity that explain heritability. Pediatr Nephrol. 2017;32:467-76.

35. McCarthy HJ, Bierzynska A, Wherlock M, Ognjanovic M, Kerecuk L, Hegde S, Feather S, Gilbert RD, Krischock L, Jones C, Sinha MD, Webb NJA, Christian M, Williams MM, Marks S, Koziell A, Welsh Gl, Saleem MA. Simultaneous sequencing of 24 genes associated with steroid-resistant nephrotic syndrome. Clin J Am Soc Nephrol. 2013;8:637-48.

36. Weber $\mathrm{S}$, Büscher AK, Hagmann H, Liebau MC, Heberle C, Ludwig M, Rath S, Alberer M, Beissert A, Zenker M, Hoyer PF, Konrad M, Klein H-G, Hoefele J. Dealing with the incidental finding of secondary variants by the example of SRNS patients undergoing targeted next-generation sequencing. Pediatr Nephrol. 2016;31:73-81.

37. Wang F, Zhang Y, Mao J, Yu Z, Yi Z, Yu L, Sun J, Wei X, Ding F, Zhang H, Xiao H, Yao Y, Tan W, Lovric S, Ding J, Hildebrandt F. Spectrum of mutations in Chinese children with steroid-resistant nephrotic syndrome. Pediatr Nephrol. 2017;32:1181-92.

38. Hinkes BG, Mucha B, Vlangos CN, Gbadegesin R, Liu J, Hasselbacher K, Hangan D, Ozaltin F, Zenker M, Hildebrandt F, Arbeitsgemeinschaft für Paediatrische Nephrologie Study Group. Nephrotic syndrome in the first year of life: two thirds of cases are caused by mutations in 4 genes (NPHS1, NPHS2, WT1, and LAMB2). Pediatrics. 2007:119:e907-19.

Ready to submit your research? Choose BMC and benefit from:

- fast, convenient online submission

- thorough peer review by experienced researchers in your field

- rapid publication on acceptance

- support for research data, including large and complex data types

- gold Open Access which fosters wider collaboration and increased citations

- maximum visibility for your research: over $100 \mathrm{M}$ website views per year

At BMC, research is always in progress.

Learn more biomedcentral.com/submissions 